Research paper

\title{
Benzofuran hydrazones as potential scaffold in the development of multifunctional drugs: Synthesis and evaluation of antioxidant, photoprotective and antiproliferative activity
}

\author{
Anna Baldisserotto b, ${ }^{\text {, }}$ Monica Demurtas ${ }^{a, 1}$, Ilaria Lampronti ${ }^{c}$, Davide Moi ${ }^{a}$, \\ Gianfranco Balboni ${ }^{\text {a }}$, Silvia Vertuani ${ }^{\text {b }}$, Stefano Manfredini ${ }^{\text {b }}$, Valentina Onnis ${ }^{\text {a, }}$ \\ a Department of Life and Environmental Sciences, Unit of Pharmaceutical, Pharmacological and Nutraceutical Sciences, University of Cagliari, Via Ospedale \\ 72, Cagliari, I-09124, Italy \\ ${ }^{\mathrm{b}}$ Department of Life Sciences and Biotechnology, University of Ferrara, Via Fossato di Mortara 17-19, Ferrara, I-44121, Italy \\ ${ }^{\mathrm{c}}$ Department of Life Sciences and Biotechnology, University of Ferrara, Via Fossato di Mortara 74, Ferrara, I-44121, Italy
}

\section{A R T I C L E I N F O}

\section{Article history:}

Received 5 June 2018

Received in revised form

29 June 2018

Accepted 1 July 2018

Available online 2 July 2018

\section{Keywords:}

Benzofuran hydrazones

Polyhydroxylated compounds

Antioxidant activity

Photoprotective agents

Antiproliferative activity

\begin{abstract}
A B S T R A C T
New benzofuranhydrazones 3-12 were easily prepared and assayed for their radical-scavenging ability. Hydrazones 3-12 showed different extent antioxidant activity in DPPH, FRAP and ORAC assays. Good antioxidant activity is related to the number and position of hydroxyl groups on the arylidene moiety. High antioxidant activity is showed by the 2-hydroxy-4-(diethylamino)benzylidene derivative $\mathbf{1 1}$. Furthermore, hydrazones 3-12 showed photoprotective capacities with satisfactory in vitro SPF as compared to the commercial PBSA sunscreen filter. The antiproliferative effects of the hydrazones 3-12 was tested on erythroleukemia K562 and Colo-38 melanoma human cells. All the compounds showed growth inhibition in the micromolar to sub micromolar concentration range. If taken together these results points to benzofuran hydrazones as potential multifunctional molecules especially in the treatment of neoplastic diseases being the good antioxidant properties of 5, $\mathbf{7}$ and $\mathbf{1 1}$ correlated to their high antiproliferative activity.
\end{abstract}

(๑) 2018 Published by Elsevier Masson SAS.

\section{Introduction}

Benzofuran nucleus is one of the most important oxygen containing heterocycles, and due to its derivatives potent biological properties has been identified as a target in medicinal chemistry. Benzofurans find application in a variety of drugs and in other field of chemistry and agriculture [1]. Therefore, benzofuran derivatives are the important scaffold for drug discovery and possess broad spectrum biological activity like antimicrobial [2-6], anti-viral [7,8] anti-cancer [9-16], anti-Alzheimer [17-20], anti-hyperlipidemic [21], antinflammatory and anticonvulsivant [22], anti-tubercular [23], anti-pyretic [24] and protein tyrosine phosphatase inhibitors [25]. The benzofuran core is widely distributed in nature, mainly contained in products of secondary plant metabolism. Moreover benzofurans occur in a great number of natural products. Many of

\footnotetext{
* Corresponding author. Tel.: +39 0706758632; fax: +390706758612.

E-mail address: vonnis@unica.it (V. Onnis).

1 These authors equally contribute to the present paper.
}

the natural benzofurans have physiological, pharmacological or toxic properties [26] and a large number of benzofuran derivatives either synthetic or naturally occurring have been reported for antioxidant activities [27,28]. Some examples of products of natural derivation, containing the benzofuran ring, are viniferin, a stilbene with powerful antioxidant properties and not only [29], while psoralene and methoxalene are used for the treatment of psoriasis and other skin diseases such as vitiligo, due to their dermoprotective effects [1]. Also the usnic acid, present in different kinds of lichens, includes in its molecular skeleton the benzofuran ring system. It is believed to be a powerful antioxidant and, at the same time, performs as photo-protective against UV rays [30]; due to this dualism, the usnic acid has great importance especially in the cosmetic field, finding use in the production of solar products.

Excessive exposure to ultraviolet radiation can cause various dermal disorders and is considered the most significant risk factor for the development of skin cancer [31]. UVB rays are responsible for direct damage to the skin, such as burns and rashes; while the UVA rays cause indirect damage, in most cases, due to the formation of reactive oxygen species (ROS) [32]. Considering that the 
negative effects of UV rays are also attributable to the overproduction of oxygen free radicals, to obtain an effective photoprotection it is crucial to reduce the amount of UV radiation reaching the epidermis and dermis, but also to counteract the ROS activity. Innovative molecules, having dual antioxidant and photoprotective activity, has been reported to prevent skin cancer, thanks to the synergistic action of the two properties of which they are endowed [33].

We previously reported some polyhydroxylated benzimidazole derivatives as radical scavengers and UV-protective agents [34] and benzimidazolehydrazone derivatives endowed with interesting antiproliferative activity on human cancer cell lines [35]. On the other hand benzofuran derivatives have been identified to exhibit cytotoxic activities against HL-60, SW480, A549, MCF-7, SMMC7721 human tumor cell lines [36] while, at best of our knowledge, benzofuran hydrazones have been reported as alpha-amylase inhibitors only [37]. Up to date however, the potential of hydroxybenzofuranhydrazone derivatives for identification of dual antioxidant-UV protecting and antiproliferative has not been explored yet. We have recently started a SAR study taking as a lead molecule the 2-phenyl-1-H-benzimidazole-5-sulfonic acid (PBSA), a well known sunscreen filter endowed with sunscreen protective activity and high level of safety. From this scaffold we have obtained, by sequential modification, very interesting multifunctional molecule especially toward neoplastic diseases.

Continuing our investigations and considering the importance of the presence of moieties allowing an extension of the conjugation to the substituted aromatic ring, which makes an essential contribution to the antioxidant activity [38], in the present work we designed, synthesized and tested for their antioxidant, UV protective and antiproliferative activities, a small library of hydroxybenzylidenebenzofuran-2-carbohydrazide derivatives.

\section{Results and discussion}

\subsection{Chemistry}

The target hydrazones 3-12 (Table 1) were synthesized as shown in Scheme 1. Ethyl benzofuran-2-carboxylate $\mathbf{1}$ was achieved by modification of a reported procedure [39] by reaction of salicylaldhehyde with ethyl bromoacetate in the presence of potassium carbonate. High yields of $1 \mathrm{H}$-benzo[d]imidazole-2carbohydrazide 2 were achieved upon refluxing for $3 \mathrm{~h}$ an ethanolic solution of the ethyl ester $\mathbf{1}$ and hydrazine hydrate. Hydrazones 3-12 were obtained in good to excellent yield by coupling the hydrazide $\mathbf{2}$ with the appropriate hydroxyarylaldehydes in ethanol. All the newly synthesized compounds were in agreement with expected analytical data. The IR and NMR spectral data are

Table 1

Antioxidant activity of the benzofuran derivatives 3-12.

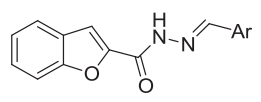

\begin{tabular}{|c|c|c|c|c|}
\hline Compd. & $\mathrm{Ar}$ & $\mathrm{DPPH}^{\mathrm{a}}(\mu \mathrm{molTE} / \mathrm{g})$ & $\mathrm{FRAP}^{\mathrm{a}}(\mu \mathrm{molTE} / \mathrm{g})$ & ORAC $^{\mathrm{a}}(\mu \mathrm{molTE} / \mathrm{g})$ \\
\hline 3 & & $45.80 \pm 2.97$ & $2293.83 \pm 20.62$ & $26059.89 \pm 46.23$ \\
\hline 4 & & $76.70 \pm 2.45$ & $1667.38 \pm 13.04$ & $6786.29 \pm 16.89$ \\
\hline 5 & & $148.51 \pm 4.92$ & $1212.75 \pm 6.45$ & $9375.99 \pm 26.70$ \\
\hline 6 & & $6202.86 \pm 30.9$ & $6966.77 \pm 28.25$ & $19003.78 \pm 26.13$ \\
\hline 7 & & $9210.10 \pm 34.85$ & $13248.57 \pm 35.89$ & $5257.42 \pm 17.21$ \\
\hline 8 & & $1140.96 \pm 6.20$ & $4023.34 \pm 8.63$ & $3560.49 \pm 6.72$ \\
\hline 9 & & $101.13 \pm 0.72$ & $3102.81 \pm 4.29$ & $10888.11 \pm 10.98$ \\
\hline 10 & & $<\mathrm{LOQ}^{\mathrm{b}}$ & $46.29 \pm 1.49$ & - \\
\hline 11 & & $1006.62 \pm 14.19$ & $4150.23 \pm 7.53$ & $22119.18 \pm 16.89$ \\
\hline 12 & & $131.57 \pm 7.09$ & $132.18 \pm 4.12$ & - \\
\hline
\end{tabular}

\footnotetext{
a Each value was obtained from three experiments (mean $\pm \mathrm{SE}$ )
}

b LOQ limit of quantification; - not tested. 


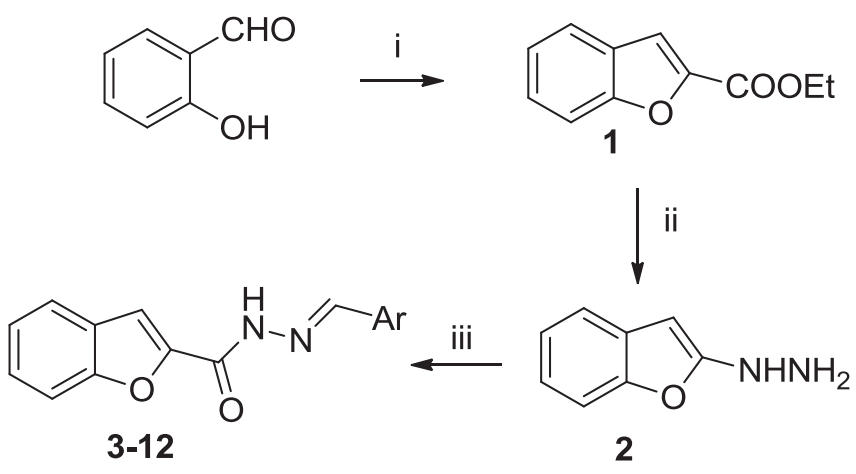

Scheme 1. Reagents and conditions: (i) Ethyl bromoacetate, $\mathrm{K}_{2} \mathrm{CO}_{3}, \mathrm{MeCN}$, reflux, $1.5 \mathrm{~h}$; (ii) $\mathrm{NH}_{2} \mathrm{NH}_{2} \cdot \mathrm{H}_{2} \mathrm{O}$, EtOH, reflux $3 \mathrm{~h}$; (iii) ArCHO, EtOH, reflux, $18 \mathrm{~h}$.

consistent with the assigned structure. According to the literature, the presence of a singlet downfield resonating $(8.27-8.87 \mathrm{ppm})$ $\underline{\mathrm{CH}}=\mathrm{N}$ signal, exclusively accounts for formation of $E$-isomers [40].

\subsection{Antioxidant activity}

The evaluation of the antioxidant properties of the hydrazones 3-12 object of this work was performed by 1,1-diphenyl-2picrylhydrazyl radical-scavenging activity (DPPH), Ferric Reducing Antioxidant Power (FRAP), and Oxygen radical absorbance capacity (ORAC) methods. Results are shown in Table 1 and are expressed as $\mu \mathrm{molTE} / \mathrm{g}$ for DPPH, FRAP, and ORAC tests. For the best interpretation of the results of the DPPH, for each compound the concentration was sought in order to inhibit $50 \%$ of the radical. From the screening of benzofuran hydrazones 3-12, by DPPH test, it can be seen that the best results, in terms of antioxidant capacity, occur when a high number of hydroxyl groups are present on the arylidene ring. The compound with the best activity was the 2,3,4trihydroxybenzylidene derivative 7 . While the 2,4,6trihydroxybenzylidene analog 8 showed a slight reduction of the antioxidant activity. The 3-hydroxybenzylidene (4) and 4hydroxybenzilidene (3) derivatives showed weak activity. The introduction of a second hydroxyl group to give hydrazone $\mathbf{5}$ led to slight improvement of activity as compared to compound $\mathbf{3}$. The displacement of 4-hydroxy group into 5-position (hydrazine 6), produced a consistent increase in the activity. The introduction of electron withdrawing groups, such as 5-chlorine atom, into benzylidene ring, even if accompanied by the electron donor effect of the 2-hydroxy group (hydrazone 10) depleted antioxidant activity. The replacement of the 4-hydroxy group of with a diethylamino moiety (hydrazone 11) restored antioxidant properties as those of the trihydroxy analog $\mathbf{8}$.

On FRAP analysis, hydrazones 3-12 resulted powerful antioxidants, except for derivatives $\mathbf{1 0}$ and 12. According to the results obtained from the DPPH test, the best performing hydrazone was the 2,3,4-trihydroxybenzilidene $\mathbf{7}$, followed by 2,5dihydroxybenzilidene derivative $\mathbf{6}$ and by the 2,4,6-trihydroxy analog 8. Significant antioxidant activity is showed by compounds $\mathbf{9}$ and $\mathbf{1 1}$ characterized by the presence in the 4-position on electron donor groups.

Through the ORAC test, it was investigated the antioxidant capacity of those compounds that had shown a satisfactory antioxidant activity with one or both the previous DPPH and FRAP tests. The ORAC test was aimed to confirm the results obtained with the previous methods and extend the activity profile for each derivative. All compounds tested exhibited a lively ability to inhibit the oxidative degradation of the fluorescent molecule, caused by peroxyl radicals. The benzofuran derivatives 3, 6 and $\mathbf{1 1}$ showed a very high ORAC antioxidant power. A significant antioxidant capacity against the peroxyl radicals was observed for compound $\mathbf{9}$. While the trihydroxybenzylidene derivatives $\mathbf{7}$ and $\mathbf{8}$ (that resulted, at the DPPH and FRAP methods, as the best derivative of the series) demonstrated the lowest activity among all tested hydrazones, but, in any case, more than appreciable.

\subsection{Evaluation of filtering properties}

The Solar Protection Factor (SPF) is related to the UV absorption of the substances, for this reason the maximum absorption wavelength $\left(\lambda_{\max }\right)$ and the molar extinction coefficient $(\varepsilon)$ of each benzofuranhydrazone derivative in methanol solution were evaluated. As a model reference compound we selected filter PBSA a commercial UV filter used since 20 years in commercial sunscreens. The benzofuran ring can be indeed considered as an isoster of the benzimidazole scaffold. The UV spectra of hydrazones 3-12 were recorded between 270 and $420 \mathrm{~nm}$ (20 nm above and below the UVA-UVB range) and compared to the reference PBSA that has a $\lambda_{\max }$ of $302 \mathrm{~nm}$; after this peak, the absorbance decreases, reaching almost zero around $325 \mathrm{~nm}$, thus not providing any absorption in the UVA region. The spectra of the new hydrazones 3-12 showed the maximum lambda shifted towards longer wavelengths, as compared to the PBSA $\lambda_{\max }$, furthermore the absorption curves of the compounds 3-12 (Figure S1 and S2) had also a wider range as compared to PBSA.

In general it has been observed that, considering the substituent on the $\mathrm{N}^{2}$ nitrogen of the hydrazone moiety, the bathochromic shift was correlated with the increase of the number of auxochromic groups present on the arylidene ring. After establishing the maximum lambda for each compound, the molar extinction coefficient (Table 2) was calculated by applying the Lambert-Beer equation.

\subsection{Determination of in vitro SPF}

In the aim to develop a new class of dualistic molecules, the synthesized hydrazones 3-12 have been evaluated as possible sunscreens. Solutions containing benzofuran derivatives were tested for their SPF efficacy in comparison with PBSA using the in vitro method of Diffey and Robson [41].

All the parameters necessary for evaluating whether a sunscreen meets the efficacy requirements, namely: the SPF value, the UVA/UVB ratio, the UVA Protection Factor value (UVAPF) and the critical wavelength $(\lambda c)$ of hydrazones 3-12 are showed in Table 2. These data were obtained by elaboration of transmittance spectra using the SPF calculator software.

The SPF value of the hydrazones 3, 4, 6, 9 and 10 was noticeable when compared to the commercial PBSA filter, used as a reference. In general, the values obtained are in agreement with what has been reported in the literature on sunscreen filters that present phenyl rings: the presence of 4-methoxy, 2-hydroxy or 4-hydroxy groups increases the filtering capacity [42]. Hydrazones 3 and $\mathbf{6}$ showed the same protection value, despite the different number and position of hydroxyl groups on the benzylidene ring. The 2,5dihydroxybenziledene derivative $\mathbf{6}$ displayed an SPF value 3.5 times higher than 2,4-dihydroxybenziledene derivative 5. Derivatives that, in absolute terms, show the best filtering capacity were hydrazones $\mathbf{4}$ and $\mathbf{1 0 .}$

Another important parameter to define the protection that a solar filter is able to provide against UV radiation is the critical wavelength, classified by the US Food and Drug Administration in five numerical categories, as follows: 0 ( $\lambda c<<325 \mathrm{~nm}), 1$ $(325 \leq \lambda c \leq 335), \quad 2(335 \leq \lambda c \leq 350), \quad 3(350 \leq \lambda c<370)$ and 4 $(\lambda c \geq 370)$ [43]. According to this classification, 4, 11 and 12 were 
Table 2

Values of $\lambda \max$ and $\varepsilon$ and UV filtering activity of the hydrazones 3-12.

\begin{tabular}{|c|c|c|c|c|c|c|}
\hline Compd. & $\lambda \max (\mathrm{nm})$ & $\varepsilon$ & $\mathrm{SPF}(\mathrm{P} \leq 0.05)$ & UVA/UVB $(P \leq 0.05)$ & UVAPF $(\mathrm{P} \leq 0.05)$ & $\lambda c^{\mathrm{a}}(\mathrm{nm})$ \\
\hline 3 & 328 & 37310 & 3.40 & 0.29 & 1.03 & 322 \\
\hline 4 & 314 & 34900 & 7.58 & 0.85 & 2.45 & 353 \\
\hline 5 & 343 & 20906 & 10.23 & 0.26 & 1.50 & 342 \\
\hline 6 & 306 & 28265 & 2.18 & 1.33 & 2.38 & 366 \\
\hline 7 & 336 & 13288 & 7.58 & 0.85 & 2.45 & 353 \\
\hline 8 & 345 & 33500 & 1.99 & 1.32 & 2.02 & 366 \\
\hline 9 & 334 & 32000 & 3.36 & 2.33 & 5.57 & 371 \\
\hline 10 & 310 & 35285 & 5.78 & 1.14 & 2.89 & 357 \\
\hline 11 & 381 & 47754 & 2.59 & 1.29 & 3.60 & 387 \\
\hline 12 & 329 & 24983 & 8.82 & 0.39 & 2.85 & 359 \\
\hline PBSA & 302 & 25000 & 1.68 & 1.27 & 5.10 & 394 \\
\hline
\end{tabular}

${ }^{\text {a }}$ Wavelength at which the integral of the spectral absorbance curve reaches $90 \%$ of the area under the curve from 290 to $400 \mathrm{~nm}$.

classified as " 4 "; $3,5,6,7,9$ and 10 as " 3 " and 4 as "2". A widespectrum solar product that is, able to protect the skin at the same time from UVB and UVA rays should have a value of $\lambda c$ above $370 \mathrm{~nm}$ [44]. According to this criterion, the only interesting benzofuran hydrazones were 8, 11 and 12. The UVA - UVB absorbance ratio is another important parameter for evaluating the absorption of a sunscreen across the full UV range: this ratio should be worth at least $1 / 3$ in according to the latest EU recommendation. With the exception of 4, all compounds 3-12 followed this indication, most of them display values greater than 1 being hydrazone 8 the best (UVA/UVB absorbance ratio value 2.33). Finally, the UVAPF value, determined according to the ISO-24443 guidelines, showed that all the compounds in the series have a better UVA Protection Factor than the reference PBSA and, in particular, the UVAPF values of hydrazones $\mathbf{8}$ and $\mathbf{1 1}$ emerged (5.57 and 5.10 respectively).

\subsection{Antiproliferative and differentiating activity}

The hydrazones 3-12 were tested on human melanoma Colo38 cell line as well as on human erythroleukemic K562 cells to determine their antiproliferative and differentiating effects [45].

All the compounds have been tested on both cell lines, in order to evaluate the relative $\mathrm{IC}_{50}$ values expressed in $\mu \mathrm{M}$ concentration (Table 3). Hydrazone $\mathbf{1 1}$ exhibited greatest activity of the series, displaying an antiproliferative effect on both the Colo38 and $\mathrm{K} 562$ cells at submicromolar concentrations ( $\mathrm{IC}_{50}$ values $0,44 \pm 0,06$ and $0,52 \pm 0,07 \mu \mathrm{M}$ respectively) while the analog 5 selectively inhibited the Colo38 cell growth $\left(\mathrm{IC}_{50}=0,57 \pm 0,12 \mu \mathrm{M}\right)$. The presence of one or more hydroxy groups and their position on arylidene ring are crucial for the activity. In fact the hydrazone of 3hydroxybenzaldehyde $\mathbf{4}$ showed antiproliferative activity at single digit micromolar $\mathrm{IC}_{50}$ values on Colo38 cell line. The shift of the hydroxyl group from the 4-position to the 3-position led to poorly

Table 3

Effects of the benzofuran derivatives on the proliferation of Colo38 and K562 cells.

\begin{tabular}{lll}
\hline Compd. & $\mathrm{IC}_{50}(\mu \mathrm{M})$ & \\
\cline { 2 - 3 } & $\mathrm{Colo38}$ & $\mathrm{K} 562$ \\
\hline $\mathbf{3}$ & $39,44 \pm 2,45$ & $79,9 \pm 6,05$ \\
$\mathbf{4}$ & $6,2 \pm 0,47$ & $52,4 \pm 6,43$ \\
$\mathbf{5}$ & $0,57 \pm 0,12$ & $4,3 \pm 0,12$ \\
$\mathbf{6}$ & $6,26 \pm 1,63$ & $36,8 \pm 2,81$ \\
$\mathbf{7}$ & $6,48 \pm 0,75$ & $6,0 \pm 0,28$ \\
$\mathbf{8}$ & $24,41 \pm 2,94$ & $64,0 \pm 5,13$ \\
$\mathbf{9}$ & $48,96 \pm 3,94$ & $5,6 \pm 0,21$ \\
$\mathbf{1 0}$ & $2,02 \pm 0,03$ & $3,7 \pm 0,14$ \\
$\mathbf{1 1}$ & $0,44 \pm 0,06$ & $0,52 \pm 0,07$ \\
$\mathbf{1 2}$ & $3,01 \pm 0,19$ & $4,5 \pm 0,78$ \\
\hline
\end{tabular}

active compound 3. The introduction of a second 2-hydroxyl group (hydrazone 5) caused an increase in activity with respect to the 4hydroxy analog 3, as well as the replacement of the 4-hydroxyl group of 5 with a diethylamino group (hydrazone 11). On the contrary the presence of the 2,5-dihydroxybenzylidene group (hydrazone 6) led to reduction in inhibitory activity as compared with compound 5. The introduction of a third hydroxyl group (compounds $\mathbf{7}$ and $\mathbf{8}$ ) resulted in slight or drastic reduction of cytostatic activity respectively as compared to $\mathbf{5}$. A comparison of substituent effects revealed that the introduction of a 2-hydroxy-5chlorobenzylidene moiety led to compound $\mathbf{1 0}$ endowed with a better antiproliferative effect as compared with 2,5dihydroxybenzylidene analog $\mathbf{6}$. The introduction of the 3hydroxy-4-methoxybenzylidene moiety (compound 9) caused a decrease in activity as compared with 3-hydroxybenzylidene analog 4.

The monohydroxylated hydrazones $\mathbf{3}$ and $\mathbf{4}$ showed poor activity against $\mathrm{K} 562$ cell line. The introduction of a second hydroxyl group (5) and third hydroxyl group (7) caused an increase in activity. The position of the three hydroxyl groups is crucial in fact the shift of 3-OH to 6-position to give compound 8 led drop in activity. As in the case of Colo38 cell line the replacement of the 4-hydroxyl group of $\mathbf{5}$ with a diethylamino group led to the best active compound of the series (hydrazone 11). The introduction on hydrazone 4 of a 4-methoxy group to give compound $\mathbf{9}$, the replacement of 2hydroxyl group of $\mathbf{6}$ with a chlorine atom to give the analog 10, as well as the replacement of the benzylidene moiety with napthylidene (12) produced improvement in the antiproliferative activity.

Benzofuran derivatives were also tested for their ability in inducing erythroid differentiation of $\mathrm{K} 562$ cells [46]. The compounds were evaluated after 5, 6 and 7 days from the onset of the treatment. Among the hydrazones 3-12 only the polyhydroxylated derivatives $\mathbf{5}$ and $\mathbf{9}$ stimulated the cells to differentiate in an erythroid direction, although the percentage of differentiation observed for these samples was to be considered minimal (about $5 \%)$.

\section{Conclusion}

Continuing our research in the aim to develop possible multifunctional drugs, we selected the benzofuran scaffold in view of its interesting known properties. Hydrazones 3-12 showed different extent of radical-scavenging ability towards the nitrogen radical by the DPPH test, to reduce ferric ion by the FRAP test and to inhibit the oxidative degradation caused by peroxyl radicals using the ORAC test. The SAR data obtained by the antioxidant screening of the benzofuran derivatives have shown good antioxidant activity and is related to the number and position of hydroxyl groups on the arylidene moiety. High antioxidant activity is showed by the 2- 
hydroxy-4-(diethylamino)benzylidene derivative 11. On the other hand, the presence of electron attractor groups, such as halogens, has consistently reduced the antioxidant capacity. The benzofuran derivatives 3-12 showed photoprotective capacities with satisfactory in vitro SPF as compared to the commercial PBSA sunscreen filter. In addition, the data obtained showed that all new benzofuran hydrazones have higher UVA filtering capacities than PBSA, since the UVA-PF, UVA/UVB and critical wavelength values are higher than those of the lead compound. To confirm the appreciable filtering activity observed in this preliminary study phase and to evaluate the possible use of such compounds as sunscreen filters, the analyzed molecules will be included in topical formulations and subjected to further evaluations. Finally, the hydrazones 3-12 inhibited the growth of human erythroleukemia cells K562 and human Colo-38 melanoma cells at micromolar and sub micromolar concentrations. If taken together these results points to benzofuran hydrazones as potential multifunctional molecules especially in the treatment of neoplastic diseases being the good antioxidant properties of 5, $\mathbf{7}$ and $\mathbf{1 1}$ correlated to their high antiproliferative activity. In particular hydrazone $\mathbf{1 1}$ is the best compound of the series on both human tumor cell lines showing sub micromolar $\mathrm{IC}_{50}$. We believe these results of interest for the scientific community to stimulate researches in the challenging field of multifunctional drugs.

\section{Experimental section}

\subsection{General methods}

All commercially available solvents and reagents were used without further purification. Standard samples were purchased from Sigma-Aldrich, Milan, Italy. NMR spectra were recorded on an Inova 500 spectrometer (Varian, Palo Alto, CA, USA). The chemical shifts $(\delta)$ are reported in part per million downfield from tetramethylsilane (TMS), which was used as internal standard, and the spectra were recorded in hexadeuteriodimethylsulphoxide $\left(\right.$ DMSO- $\left.d_{6}\right)$. Infrared spectra were recorded on a Vector 22 spectrometer (Bruker, Bremen, Germany) in Nujol mulls. The main bands are given in $\mathrm{cm}-1$. Positive-ion electrospray ionization (ESI) mass spectra were recorded on a double-focusing MAT 95 instrument (Finnigan, Waltham, MA, USA) with BE geometry. Melting points (mp) were determined on a SMP1 Melting Point apparatus (Stuart Scientific, Stone, UK) and are uncorrected. All products reported showed ${ }^{1} \mathrm{H}$ NMR spectra in agreement with the assigned structures. The purity of the tested compounds was determined by combustion elemental analyses conducted by the Microanalytical Laboratory of the Chemistry Department of the University of Ferrara with a MT-5 CHN recorder elemental analyzer (Yanagimoto, Kyoto, Japan) and the values found were within $0.4 \%$ of theoretical values. The spectrophotometer used for antioxidant analysis is a Beckman Coulter Tм, DU ${ }^{\mathbb{R}} 530$, Life Science UV/VIS spectrophotometer, Single Cell Module. The instrument used to conduct ORAC analyzes is the Thermo Fluoroskan Ascent FL ${ }^{\circledR}$ Microplate Fluorometer and Luminometer, linked to Ascent Software ${ }^{\circledR}$ software for data control and processing. In the sample loading phase, 96-well plates with a black background were used. Spectrophotometric analysis for the detection of filter parameters were conducted with a UV-VIS spectrophotometer SHIMADZU UV-2600 $240 \mathrm{~V}$.

\subsection{Chemistry}

\subsubsection{Ethyl benzofuran-2-carboxylate (1)}

To a mixture of salicylaldehyde $(1.22 \mathrm{~g}, 0.01 \mathrm{~mol})$ and $\mathrm{MeCN}$ $(10 \mathrm{~mL})$, were added ethyl bromoacetate $(1.1 \mathrm{~mL}, 0.01 \mathrm{~mol})$ and $\mathrm{K}_{2} \mathrm{CO}_{3}(2.76 \mathrm{~g}, 0.02 \mathrm{~mol})$. The reaction mixture was refluxed for
$1.5 \mathrm{~h}$. After cooling to $\mathrm{r}$. $\mathrm{t}$. the reaction mixture was poured into crushed ice. Then product was extracted using ethyl acetate $(50 \mathrm{~mL} \times 3)$, the combined organic layer was washed using brine solution $(20 \mathrm{~mL} \times 2)$. The organic layer was dried using anhydrous sodium sulphate and the solvent evaporated under reduced pressure to afford the product as oil. Yield $80 \%$, bp $274-276^{\circ} \mathrm{C}$. (Lit. $\left.276{ }^{\circ} \mathrm{C}[47]\right) .{ }^{1} \mathrm{H}$ NMR (DMSO- $\left.d_{6}\right): \delta 1.33\left(\mathrm{t}, J=7.5 \mathrm{~Hz}, 3 \mathrm{H}, \mathrm{CH}_{3}\right), 4.37$ $\left(\mathrm{q}, J=7.5 \mathrm{~Hz}, 2 \mathrm{H}, \mathrm{CH}_{2}\right), 7.35(\mathrm{~m}, 1 \mathrm{H}, \mathrm{Ar}), 7.50(\mathrm{~m}, 1 \mathrm{H}, \mathrm{Ar}), 7.71-7.80$ (m, 3H, Ar). IR (neat) 2984, 1731, 1614, $1563 \mathrm{~cm}^{-1} \mathrm{~m} / z 191(\mathrm{M}+\mathrm{H})^{+}$. Anal. Calcd for $\mathrm{C}_{11} \mathrm{H}_{11} \mathrm{O}_{3}$ : C, 69.46; $\mathrm{H}, 5.30$. Found: $\mathrm{C}, 69.39 ; \mathrm{H}, 5.32$.

\subsubsection{Benzofuran-2-carbohydrazide (2)}

A mixture of ethyl benzofuran-2-carboxylate 1 (3.80 g, $20 \mathrm{mmol}$ ), and hydrazine monohydrate ( $3 \mathrm{~mL}, 61.5 \mathrm{mmol}$ ) in EtOH $(5 \mathrm{~mL})$ was refluxed for $3 \mathrm{~h}$. After cooling the formed precipitate was filtered off, washed with water $(5 \times 10 \mathrm{~mL})$ dried and used without further purification. Yield $85 \%$. Mp $190-192{ }^{\circ} \mathrm{C}$ (lit. 190-194 $\left.{ }^{\circ} \mathrm{C}[47]\right) .{ }^{1} \mathrm{H}$ NMR (DMSO- $\left.d_{6}\right): \delta 4.56\left(\mathrm{~s}, 2 \mathrm{H}, \mathrm{NH}_{2}\right), 7.31(\mathrm{~m}$, $1 \mathrm{H}, \mathrm{Ar}), 7.42(\mathrm{~m}, 1 \mathrm{H}, \mathrm{Ar}), 7.50(\mathrm{~s}, 1 \mathrm{H}, \mathrm{Ar}), 7.63(\mathrm{~d}, J=8.5 \mathrm{~Hz}, 1 \mathrm{H}, \mathrm{Ar})$, 7.74 (d, $J=8.0 \mathrm{~Hz}, 1 \mathrm{H}, \mathrm{Ar}$ ), 10.00 (s, 1H, NH). IR (Nujol) 3322, 3184, $1661,1601 \mathrm{~cm}^{-1} \mathrm{~m} / z 177(\mathrm{M}+\mathrm{H})^{+}$. Anal. Calcd for $\mathrm{C}_{9} \mathrm{H}_{8} \mathrm{~N}_{2} \mathrm{O}_{2}$ : C, 61.36; H, 4.58; N, 15.90. Found: C, 61.29; H, 4.59; N, 15.93.

\subsubsection{General procedure for the synthesis of hydrazones (3-16)}

A mixture of hydrazide $2(1 \mathrm{mmol})$ and the appropriate aldehyde $(1 \mathrm{mmol})$ in EtOH $(10 \mathrm{~mL})$ was refluxed for $18 \mathrm{~h}$. After cooling the formed precipitate was filtered off and purified by crystallization from the adequate solvent to give the hydrazone derivatives.

4.2.3.1. (E)-N'-(4-hydroxybenzylidene)benzofuran-2-carbohydrazide (3). Yield $79 \% . \mathrm{Mp}>250{ }^{\circ} \mathrm{C}(\mathrm{EtOH}) .{ }^{1} \mathrm{H}$ NMR (DMSO- $\left.d_{6}\right): \delta 6.85(\mathrm{~d}$, $J=8.0 \mathrm{~Hz}, 2 \mathrm{H}, \mathrm{Ar}), 7.36(\mathrm{t}, J=7.0 \mathrm{~Hz}, 1 \mathrm{H}, \mathrm{Ar}), 7.49(\mathrm{t}, J=8.0 \mathrm{~Hz}, 1 \mathrm{H}$, $\mathrm{Ar}), 7.57(\mathrm{~d}, J=8.0 \mathrm{~Hz}, 2 \mathrm{H}, \mathrm{Ar}), 7.68(\mathrm{~d}, J=8.0 \mathrm{~Hz}, 2 \mathrm{H}, \mathrm{Ar}), 7.81(\mathrm{~s}, 1 \mathrm{H}$, $\mathrm{Ar}), 8.41(\mathrm{~s}, 1 \mathrm{H}, \mathrm{CH}), 9.95(\mathrm{~s}, 1 \mathrm{H}, \mathrm{OH}), 11.93(\mathrm{~s}, 1 \mathrm{H}, \mathrm{NH}) .{ }^{13} \mathrm{C}$ NMR (DMSO- $d_{6}$ ): $\delta 110.00,112.41,113.63,115.00,118.92$ (2C), 125.98, 126.96, 128.28, 130.24 (2C), 132.19, 151.34, 152.24, 157.54, 162.79. IR (Nujol) 3289, 1624, $1600 \mathrm{~cm}^{-1} \mathrm{~m} / \mathrm{z} 282(\mathrm{M}+\mathrm{H})^{+}$. Anal. Calcd for $\mathrm{C}_{16} \mathrm{H}_{12} \mathrm{~N}_{2} \mathrm{O}_{3}$ : C, 68.56; H, 4.32; N, 9.99. Found: C, 68.59; H, 4.31; N, 10.03 .

4.2.3.2. (E)-N'-(3-hydroxybenzylidene)benzofuran-2-carbohydrazide (4). Yield 93\%. Mp $221-223{ }^{\circ} \mathrm{C}\left(\right.$ EtOH). ${ }^{1} \mathrm{H}$ NMR (DMSO-d $\left.d_{6}\right): \delta 6.83$ $(\mathrm{d}, J=8.0 \mathrm{~Hz}, 1 \mathrm{H}, \mathrm{Ar}), 6.85(\mathrm{~d}, J=8.0 \mathrm{~Hz}, 1 \mathrm{H}, \mathrm{Ar}), 7.11-7.75(\mathrm{~m}, 4 \mathrm{H}$, Ar), $7.81(\mathrm{~d}, J=8.0 \mathrm{~Hz}, 1 \mathrm{H}, \mathrm{Ar}), 7.68(\mathrm{~d}, J=8.0 \mathrm{~Hz}, 1 \mathrm{H}, \mathrm{Ar}), 7.81(\mathrm{~s}, 1 \mathrm{H}$, Ar) $8.43(\mathrm{~s}, 1 \mathrm{H}, \mathrm{CH}), 9.62(\mathrm{~s}, 1 \mathrm{H}, \mathrm{OH}), 12.09(\mathrm{~s}, 1 \mathrm{H}, \mathrm{NH}) .{ }^{13} \mathrm{C}$ NMR $\left(\right.$ DMSO- $\left.d_{6}\right): \delta 110.00,113.98,115.01,115.91,120.82(2 \mathrm{C}), 122.10$, 126.05, 127.02, 130.37, 133.07, 139.56, 152.00, 157.8, 160.86 (2C). IR (Nujol) 3265, 1662, 1612, $1580 \mathrm{~cm}^{-1} \mathrm{~m} / \mathrm{z} 282(\mathrm{M}+\mathrm{H})^{+}$. Anal. Calcd for $\mathrm{C}_{16} \mathrm{H}_{12} \mathrm{~N}_{2} \mathrm{O}_{3}$ : C, 68.56; $\mathrm{H}, 4.32 ; \mathrm{N}, 9.99$. Found: $\mathrm{C}, 68.61 ; \mathrm{H}, 4.33$; $\mathrm{N}, 9.96$

4.2.3.3. (E)-N'-(2,4-dihydroxybenzylidene)benzofuran-2carbohydrazide (5). Yield $74 \%$. Mp $234{ }^{\circ} \mathrm{C}$ dec (EtOH). ${ }^{1} \mathrm{H}$ NMR (DMSO-d $d_{6}$ ): $\delta$ 6.32-6.38 (m, 2H, Ar), 7.32-7.38 (m, 2H, Ar), 7.51 (s, 1H, Ar), 7.70-7.81 (m, 3H, Ar), $8.59(\mathrm{~s}, 1 \mathrm{H}, \mathrm{CH}), 9.91(\mathrm{~s}, 1 \mathrm{H}, \mathrm{OH}), 11.20$ $(\mathrm{s}, 1 \mathrm{H}, \mathrm{OH}), 12.20(\mathrm{~s}, 1 \mathrm{H}, \mathrm{NH}) .{ }^{13} \mathrm{C}$ NMR (DMSO- $\left.d_{6}\right): \delta 110.00,110.57$, 115.73, 118.45, 118.67, 119.65, 130.81, 131.78, 134.90, 135.11, 139.20, 155.71, 157.87, 162.05, 162.34, 167.42. IR (Nujol) $1627,1610 \mathrm{~cm}^{-1} \mathrm{~m} / \mathrm{z}$ $297(\mathrm{M}+\mathrm{H})^{+}$. Anal. Calcd for $\mathrm{C}_{16} \mathrm{H}_{12} \mathrm{~N}_{2} \mathrm{O}_{4}$ : C, 64.86; $\mathrm{H}, 4.08 ; \mathrm{N}, 9.46$. Found: C, 64.91; H, 4.06; N, 9.50.

4.2.3.4. (E)-N'-(2,5-dihydroxybenzylidene)benzofuran-2carbohydrazide (6). Yield 54\%. Mp $>250{ }^{\circ} \mathrm{C}(\mathrm{EtOH}) .{ }^{1} \mathrm{H}$ NMR (DMSO- $d_{6}$ ): $\delta 6.72$ (d, $J=7.0 \mathrm{~Hz}, 2 \mathrm{H}, \mathrm{Ar}$ ), 7.01 (s, 1H,Ar), 7.35-7.38 (m, 2H, Ar), 7.70-7.83 (m, 3H, Ar), $8.66(\mathrm{~s}, 1 \mathrm{H}, \mathrm{CH}), 9.00(\mathrm{~s}, 1 \mathrm{H}, \mathrm{OH})$, 
$10.20(\mathrm{~s}, 1 \mathrm{H}, \mathrm{OH}), 12.29$ (s, $1 \mathrm{H}, \mathrm{NH}) .{ }^{13} \mathrm{C}$ NMR (DMSO- $\left.d_{6}\right): \delta 109.99$, 118.84, 119.77, 121.47 (2C), 125.05, 127.00, 127.12, 130.85, 131.90, 134.88, 135.18, 152.20, 157.84, 158.16, 162.37. IR (Nujol) 1661, $1597 \mathrm{~cm}^{-1} \mathrm{~m} / z 297(\mathrm{M}+\mathrm{H})^{+}$. Anal. Calcd for $\mathrm{C}_{16} \mathrm{H}_{12} \mathrm{~N}_{2} \mathrm{O}_{4}: \mathrm{C}, 64.86$; H, 4.08; N, 9.46. Found: C, 64.80; H, 4.07; N, 9.43.

4.2.3.5. (E)-N'-(2,3,4-trihydroxybenzylidene)benzofuran-2carbohydrazide (7). Yield 53\%. Mp $>250{ }^{\circ} \mathrm{C}(\mathrm{EtOH}) .{ }^{1} \mathrm{H}$ NMR (DMSO- $d_{6}$ ): $\delta 6.40$ (d, $\left.J=8.5 \mathrm{~Hz}, 1 \mathrm{H}, \mathrm{Ar}\right), 6.80$ (d, $J=8.5 \mathrm{~Hz}, 1 \mathrm{H}, \mathrm{Ar}$ ), 7.35-7.81 (m, 5H, Ar), $8.55(\mathrm{~s}, 1 \mathrm{H}, \mathrm{CH}), 9.82(\mathrm{~s}, 1 \mathrm{H}, \mathrm{OH}), 11.20(\mathrm{~s}, 1 \mathrm{H}$, $\mathrm{OH}), 12.15(\mathrm{~s}, 1 \mathrm{H}, \mathrm{NH}), 13.10(\mathrm{~s}, 1 \mathrm{H}, \mathrm{OH}) .{ }^{13} \mathrm{C}$ NMR (DMSO-d $): \delta 109.9$ (2C), 115.68, 118.78, 119.77, 129.13, 130.83, 131.81, 134.90, 135.15, $140.65,155.48,155.66,156.88,162.05,162.35$. IR (Nujol) 3341, 1655, $1595 \mathrm{~cm}^{-1} \mathrm{~m} / \mathrm{z} 313(\mathrm{M}+\mathrm{H})^{+}$. Anal. Calcd for $\mathrm{C}_{16} \mathrm{H}_{12} \mathrm{~N}_{2} \mathrm{O}_{5}$ : C, 61.54; H, 3.87; N, 8.97. Found: C, 61.59; H, 3.86; N, 9.01.

4.2.3.6. (E)-N'-(2,4,6-trihydroxybenzylidene)benzofuran-2carbohydrazide (8). Yield 60\%. Mp $248{ }^{\circ} \mathrm{C}$ dec (EtOH). ${ }^{1} \mathrm{H}$ NMR (DMSO- $d_{6}$ ): $\delta 5.85$ (s, 2H, Ar), 7.34-7.80 (m, 5H, Ar), $8.87(\mathrm{~s}, 1 \mathrm{H}, \mathrm{CH}$ ), $9.83(\mathrm{~s}, 1 \mathrm{H}, \mathrm{OH}), 11.03(\mathrm{~s}, 2 \mathrm{H}, \mathrm{OH}), 12.24(\mathrm{~s}, 1 \mathrm{H}, \mathrm{NH}) .{ }^{13} \mathrm{C} \mathrm{NMR}$ (DMSO- $d_{6}$ ): $\delta 97.56$ (2C), 102.23, 113.78, 115.00, 126.04, 127.01, $130.15,130.24,140.30,150.88,157.04,157.58$ (2C), 162.98, 164.98. IR (Nujol) 3341, 1655, $1596 \mathrm{~cm}^{-1} \mathrm{~m} / \mathrm{z} 313(\mathrm{M}+\mathrm{H})^{+}$. Anal. Calcd for $\mathrm{C}_{16} \mathrm{H}_{12} \mathrm{~N}_{2} \mathrm{O}_{5}$ : C, 61.54; $\mathrm{H}, 3.87$;, 8.97 . Found: C, 61.49; H, 3.86; N, 8.94 .

4.2.3.7. (E)-N'-(4-hydroxy-3-methoxybenzylidene)benzofuran-2carbohydrazide (9). Yield 84\%. Mp $192-193^{\circ} \mathrm{C}$ (EtOH). ${ }^{1} \mathrm{H}$ NMR (DMSO-d 6 ): $\delta 3.81\left(\mathrm{~s}, 3 \mathrm{H}, \mathrm{OCH}_{3}\right), 6.99$ (d, $\left.J=8.0 \mathrm{~Hz}, 1 \mathrm{H}, \mathrm{Ar}\right), 7.07$ (d, $J=8.0 \mathrm{~Hz}, 1 \mathrm{H}, \mathrm{Ar}), 7.30-7.81(\mathrm{~m}, 6 \mathrm{H}, \mathrm{Ar}), 8.38(\mathrm{~s}, 1 \mathrm{H}, \mathrm{CH}), 9.30(\mathrm{~s}, 1 \mathrm{H}$, $\mathrm{OH}), 12.01(\mathrm{~s}, 1 \mathrm{H}, \mathrm{NH}) .{ }^{13} \mathrm{C}$ NMR $\left(\mathrm{DMSO}_{-} \mathrm{d}_{6}\right): \delta 56.75,110.01,113.72$, 115.00, 115.07, 115.58, 123.65, 126.00, 126.98, 130.18, 130.27, 150.09, 152.07, 153.19, 153.78, 157.63, 160.60. IR (Nujol) 3230, 1643, $1609 \mathrm{~cm}^{-1} \mathrm{~m} / z 311(\mathrm{M}+\mathrm{H})^{+}$. Anal. Calcd for $\mathrm{C}_{17} \mathrm{H}_{14} \mathrm{~N}_{2} \mathrm{O}_{4}$ : C, 65.80; H, 4.55; N, 9.03. Found: C, 65.89; H, 4.54; N, 8.99.

4.2.3.8. (E)-N'-(5-chloro-2-hydroxybenzylidene)benzofuran-2carbohydrazide (10). Yield 76\%. Mp $>250^{\circ} \mathrm{C}$ dec (EtOH). (lit 293-295 ${ }^{\circ} \mathrm{C}[48] .{ }^{1} \mathrm{H}$ NMR (DMSO-d 6 ): $\delta 6.95(\mathrm{~d}, J=9.0 \mathrm{~Hz}, 1 \mathrm{H}, \mathrm{Ar}$ ), 7.31 (m, 2H, Ar), 7.49 (m, 1H, Ar), 7.53-7.83 (m, 4H, Ar), $8.71(\mathrm{~s}, 1 \mathrm{H}$, $\mathrm{CH}), 11.11(\mathrm{~s}, 1 \mathrm{H}, \mathrm{OH}), 12.48(\mathrm{~s}, 1 \mathrm{H}, \mathrm{NH}) .{ }^{13} \mathrm{C}$ NMR (DMSO-d 6 ): $\delta 119.12,119.80,126.14,128.68,130.90,130.96,131.82,134.83$, 135.27, 138.86, 154.21, 154.38, 155.43, 162.40, 162.50, 163.93. IR (Nujol) 3177, 1657, $1605 \mathrm{~cm}^{-1} \mathrm{~m} / \mathrm{z} 311(\mathrm{M}+\mathrm{H})^{+}$. Anal. Calcd for $\mathrm{C}_{16} \mathrm{H}_{11} \mathrm{ClN}_{2} \mathrm{O}_{3}$ : C, 61.06; H, 3.52; N, 8.90. Found: $\mathrm{C}, 61.00 ; \mathrm{H}, 3.53 ; \mathrm{N}$, 8.94 .

4.2.3.9. (E)-N'-(4-(diethylamino)-2-hydroxybenzylidene)benzofuran2-carbohydrazide (11). Yield $74 \%$ Mp $105-106{ }^{\circ} \mathrm{C}\left(\right.$ EtOH). ${ }^{1} \mathrm{H}$ NMR (DMSO-d $)_{6}$ ): $\delta 1.10$ (t, $\left.J=7.0 \mathrm{~Hz}, 6 \mathrm{H}, \mathrm{CH}_{3}\right), 3.34(\mathrm{~d}, J=7.0 \mathrm{~Hz}, 4 \mathrm{H}$, $\left.\mathrm{CH}_{2}\right), 6.12(\mathrm{~s}, 1 \mathrm{H}, \mathrm{Ar}), 6.26(\mathrm{~d}, J=6.0 \mathrm{~Hz}, 1 \mathrm{H}, \mathrm{Ar}), 7.19(\mathrm{~d}, J=6.0 \mathrm{~Hz}$, $1 \mathrm{H}, \mathrm{Ar}), 7.34(\mathrm{~m}, 2 \mathrm{H}, \mathrm{Ar}), 7.50-7.81(\mathrm{~m}, 3 \mathrm{H}, \mathrm{Ar}), 8.50(\mathrm{~s}, 1 \mathrm{H}, \mathrm{CH}), 11.31$ $(\mathrm{s}, 1 \mathrm{H}, \mathrm{OH}), 12.14(\mathrm{~s}, 1 \mathrm{H}, \mathrm{NH}) .{ }^{13} \mathrm{C}$ NMR (DMSO- $\left.d_{6}\right): \delta 20.43(2 \mathrm{C})$, 51.71 (2C), 105.38, 110.00, 111.69, 114.32, 118.42, 119.74, 130.74, $131.75,134.95,135.01,139.54,155.90,158.26,158.56,162.31,167.66$. IR (Nujol) 1628, $1602 \mathrm{~cm}^{-1} \mathrm{~m} / \mathrm{z} 352(\mathrm{M}+\mathrm{H})^{+}$. Anal. Calcd for $\mathrm{C}_{20} \mathrm{H}_{21} \mathrm{~N}_{3} \mathrm{O}_{3}$ : C, 68.36; $\mathrm{H}, 6.02 ; \mathrm{N}, 11.96$. Found: C, 68.41; H, 5.99; N, 12.01 .

4.2.3.10. (E)-N'-((2-hydroxynaphthalen-1-yl)methylene)benzofuran2-carbohydrazide (12). Yield 73\%. Mp $238-239{ }^{\circ} \mathrm{C}(\mathrm{EtOH}) .{ }^{1} \mathrm{H}$ NMR (DMSO- $d_{6}$ ): $\delta 7.24$ (d, $\left.J=9.0 \mathrm{~Hz}, 1 \mathrm{H}, \mathrm{Ar}\right), 7.36(\mathrm{~d}, J=7.5 \mathrm{~Hz}, 1 \mathrm{H}, \mathrm{Ar})$, 7.38 (d, $J=7.5 \mathrm{~Hz}, 1 \mathrm{H}, \mathrm{Ar}), 7.40-7.64(\mathrm{~m}, 3 \mathrm{H}, \mathrm{Ar}), 7.73-7.95(\mathrm{~m}, 5 \mathrm{H}$, $\mathrm{Ar}), 8.27(\mathrm{~s}, 1 \mathrm{H}, \mathrm{CH}), 9.59(\mathrm{~s}, 1 \mathrm{H}, \mathrm{OH}), 12.52(\mathrm{~s}, 1 \mathrm{H}, \mathrm{NH}) .{ }^{13} \mathrm{C} \mathrm{NMR}$ $\left(\right.$ DMSO- $\left.d_{6}\right): \delta 110.00,111.72,114.49,114.99,121.96,123.91$ (2C),
126.14, 126.69, 127.07, 130.16, 131.00, 132.11, 134.84, 136.18, 150.72, 151.08, 157.32, 157.67, 161.27. IR (Nujol) 3324, 1674, $1583 \mathrm{~cm}^{-1} \mathrm{~m} / \mathrm{z}$ $331(\mathrm{M}+\mathrm{H})^{+}$. Anal. Calcd for $\mathrm{C}_{20} \mathrm{H}_{14} \mathrm{~N}_{2} \mathrm{O}_{3}$ : C, 72.72; $\mathrm{H}, 4.27 ; \mathrm{N}, 8.48$. Found: C, 72.67; H, 4.28; N, 8.52.

\subsection{Biological assays}

\subsubsection{Free radical scavenging activity on $D P P H$}

The DPPH assay measures the hydrogen donation ability of an antioxidant to convert the stable DPPH free radical into 1,1diphenyl-2-picrylhydrazyl. This can be evaluated by measuring the percent decrease in absorbance of the solution at $517 \mathrm{~nm}$, which is accompanied by a change of color from deep-violet to lightyellow, after the radical reaction with products to be tested. The radical-scavenging activity is expressed as inhibition ratio of initial concentration of DPPH radical and is calculated according to the formula:

\section{Inhibition percentage $(\mathrm{Ip})=[(\mathrm{AB}-\mathrm{As}) / \mathrm{AB}] \bullet 100$}

where $\mathrm{AB}$ and $\mathrm{As}$ are, respectively, the absorbance values of blank reaction and of the tested sample [49]. To $1.5 \mathrm{~mL}$ DPPH methanolic solution was added $0.750 \mathrm{~mL}$ of compound solution proper diluted. Samples absorbance measurements were evaluated with a UV-VIS spectrophotometer at fixed wavelength of $517 \mathrm{~nm}$. Blank sample was prepared adding methanol to DPPH solution and Trolox (6hydroxy-2,5,7,8-tetramethylchroman-2-carboxylic acid) was used as standard reference to achieve a calibration curve.

\subsubsection{Ferric ion reducing antioxidant power (FRAP) test}

In agreement with a modified protocol previously described [50] the ferric ion reducing ability of each compound solution. The analysis reagent was freshly prepared by mixing the subsequent solutions in the fixed ratio $10: 1: 1(\mathrm{v} / \mathrm{v} / \mathrm{v}): 1)$ ) $0.1 \mathrm{M}$ Acetate buffer, pH 3.6; 2) TPTZ (2,4,6-tripyridylstriazine), $10 \mathrm{mM}$ in $40 \mathrm{mM} \mathrm{HCl}, 3$ ) $\mathrm{FeCl}_{3}, 20 \mathrm{mM}$. To a $1.9 \mathrm{~mL}$ of reagent were added $0.1 \mathrm{~mL}$ of sample proper diluted or solvent when blank was performed. Readings were done after $10 \mathrm{~min}$, using a UV-VIS spectrophotometer at fixed wavelength of the absorption maximum (593 nm). It was evaluated the absorbance increase of sample solution against the absorbance of blank reaction as parameter to calculate the antioxidant activity. The antioxidant activity is given as Trolox activity since this standard was used to perform the calibration curves.

\subsubsection{Oxygen radical absorbance capacity (ORAC)}

The ORAC assay was based on that reported by Hong, Guohua \& Ronald as modified in our previous work [51] and was carried out using fluorescent filters (excitation wavelength: $485 \mathrm{~nm}$; emission filter: $538 \mathrm{~nm}$ ). In the final assay mixture ( $0.2 \mathrm{~mL}$ total volume), fluorescein sodium salt ( $85 \mathrm{nM})$ was used as a target of free radical attack with 2,2'-azobis(2-amidinopropane) dihydrochloride (AAPH) as a peroxyl radical generator. Trolox was used as a standard control: a calibration curve was carried out with solutions at different concentrations (from 40 to $240 \mu \mathrm{M}$ ). The tested compounds were dissolved in methanol and diluted in phosphate buffer solution pH 7.4 (PBS). The fluorescence measurements, carried out at $37^{\circ} \mathrm{C}$, were recorded at $5 \mathrm{~min}$ intervals up $30 \mathrm{~min}$ after the addition of AAPH. The ORAC values, calculated as difference of the areas under the quenching curves of fluoresceine between the blank and the sample, were expressed as $\mu \mathrm{mol}$ Trolox equivalents (TE) per gram of compound.

\subsubsection{Evaluation of filtering parameters}

The method followed is an adaptation of the official method for determining the value of SPF in vitro [52]. Methanolic solutions 
were prepared $0.000034( \pm 0.0000033) \mathrm{M}$ of the benzofuran hydrazones 3-12 and each of the absorption spectra was recorded.

In order to calculate the SPF value in vitro, the absorbance values obtained were transformed into transmittance values, using the equation below:

$$
A(\lambda)=-\log [T(\lambda)]
$$

The transmittance spectrum was elaborated with the SPF calculator software (version 2.1, Shimadzu, Milan, Italy) to obtain the values of SPF, UVA/UVB, UVAPF and $\lambda$ critical.

\subsubsection{Growth inhibition assays}

Cell growth inhibition assays were carried out using two human cancer cell lines, melanoma Colo38 and erythroleukemia K562 [53,54]. Cell lines were maintained in RPMI 1640, supplemented with $10 \%$ fetal bovine serum (FBS), penicillin (100 Units $\mathrm{mL}^{-1}$ ), streptomycin $\left(100 \mu \mathrm{g} \mathrm{mL}^{-1}\right)$ and glutamine $(2 \mathrm{mM})$ (complete medium); the $\mathrm{pH}$ of the medium was 7.2 and the incubation was performed at $37^{\circ} \mathrm{C}$ in a $5 \% \mathrm{CO}_{2}$ atmosphere.

Benzofuran hydrazones were solved in $\mathrm{MeOH} / \mathrm{DMSO} 10 \%$ to obtain $20 \mathrm{mM}$ stock solutions and diluted before cell treatment in $\mathrm{MeOH}$. All the compounds were added at serial dilutions to the cell cultures and incubated for 7 days. After 3 days, cells were suspended in physiological solution and counted with a Z2 Coulter Counter (Coulter Electronics, Hialeah, FL, USA). The cell number $/ \mathrm{ml}$ was determined as $\mathrm{IC}_{50}$ (concentration producing $50 \%$ growth inhibition) when untreated cells are in log phase of cell growth. Untreated cells were placed in every plate as negative control.

\subsubsection{Erythroid differentiation on K562 cell line}

After 5 days differentiation was assayed by cell benzidinestaining, utilizing solutions containing $0.2 \%$ benzidine in $5 \mathrm{M}$ glacial acetic acid, $10 \% \mathrm{H}_{2} \mathrm{O}_{2}$ as previously described [46].

\section{Acknowledgment}

This work was supported by University of Ferrara (Grant FAR 2017 to SM, SV and IL), Ambrosialab srl (Ferrara, Italy) and by University of Cagliari (Grant FIR 2017 to GB and VO).

\section{Appendix A. Supplementary data}

Supplementary data related to this article can be found at https://doi.org/10.1016/j.ejmech.2018.07.001.

\section{References}

[1] K.H. Shamsuzzaman, Bioactive Benzofuran derivatives: a review, Eur. J. Med. Chem. 97 (2015) 483-504.

[2] A. Sortase, W. He, Y. Zhang, J. Bao, X. Deng, J. Batara, S. Casey, Q. Guo, F. Jiang, L. Fu, Synthesis, biological evaluation and molecular docking analysis of 2phenyl-benzofuran-3-carboxamide derivatives as potential inhibitors of Staphylococcus aureus, Bioorg. Med. Chem. 25 (2017) 1341-1351.

[3] H.A. Abdel-Aziz, A.A. Mekawey, K.M. Dawood, Convenient synthesis and antimicrobial evaluation of some novel 2-substituted-3-methylbenzofuran derivatives, Eur. J. Med. Chem. 44 (2009) 3637-3644.

[4] H.A. Abdel-Aziz, A.A. Mekawey, Stereoselective synthesis and antimicrobial activity of benzofuran-based (1E)-1-(piperidin-1-yl)-N2-arylamidrazones, Eur. J. Med. Chem. 44 (2009) 4985-4997.

[5] S.M. Rida, S.A. El-Hawash, H.T. Fahmy, A.A. Hazza, M.M. El-Meligy, Synthesis of novel benzofuran and related benzimidazole derivatives for evaluation of in vitro anti-HIV-1, anticancer and antimicrobial activities, Arch Pharm. Res. (Seoul) 29 (2006) 826-833.

[6] A. Hiremathad, M.R. Patil, K.R. Chetna, K. Chand, M.A. Santos, R.S. Keri, Benzofuran: an emerging scaffold for antimicrobial agents, RSC Adv. 5 (2015) 96809-96828.

[7] M. Zhong, E. Peng, N. Huang, Q. Huang, A. Huq, M. Lau, R. Colonno, L. Li, Discovery of novel potent HCV NS5B polymerase non-nucleoside inhibitors bearing a fused benzofuran scaffold, Bioorg. Med. Chem. Lett 28 (2018)
963-968.

[8] J.R. Hwu, N.K. Gupta, S.C. Tsay, W.C. Huang, I.C. Albulescu, K. Kovacikova, M.J. van Hemert, Bis(benzofuran-thiazolidinone)s and bis(benzofuranthiazinanone)s as inhibiting agents for chikungunya virus, Antivir. Res. 146 (2017) 96-101.

[9] K.M. Amin, Y.M. Syam, M.M. Anwar, H.I. Ali, T.M. Abdel-Ghani, A.M. Serry, Synthesis and molecular docking study of new benzofuran and furo[3,2-g] chromone-based cytotoxic agents against breast cancer and p38 $\alpha$ MAP kinase inhibitors, Bioorg. Chem. 76 (2018) 487-500.

[10] B. Lu, S. Huang, J. Cao, Q. Hu, R. Shen, H. Wan, D. Wang, J. Yuan, L. Zhang, J. Zhang, M. Zhang, W. Tao, L. Zhang, Discovery of EBI-1051: a novel and orally efficacious MEK inhibitor with benzofuran scaffold, Bioorg. Med. Chem. 26 (2018) 581-589.

[11] T.T. Nguyen, T. Lomberget, N.C. Tran, E. Colomb, L. Nachtergaele, S. Thoret, J. Dubois, J. Guillaume, R. Abdayem, M. Haftek, R. Barret, Synthesis and biological evaluation of novel heterocyclic derivatives of combretastatin A-4, Bioorg. Med. Chem. Lett 22 (2012) 7227-7231.

[12] M.O. Abdelhafez, K.M. Amin, H.I. Ali, M.M. Abdallad, Ahmed E.Y. Synthesis and evaluation of novel benzofuran derivatives as selective SIRT2 inhibitors, RSC Adv. 4 (2014) 11569-11579.

[13] Y. Zhou, H. Cui, X. Yu, T. Peng, G. Wang, X. Wen, Y. Sun, S. Liu, S. Zhang, L. Hu L. Wang, Design, synthesis, and evaluation of benzofuran derivatives as novel anti-pancreatic carcinoma agents via interfering the hypoxia environment by targeting HIF-1 $\alpha$ pathway, Molecules 22 (2017). E1348.

[14] X.L. Xu, Y.R. Yang, X.F. Mo, J.L. Wei, X.J. Zhang, Q.D. You, Novel 1-(7-ethoxy-1benzofuran-2-yl) substituted chalcone derivatives: synthesis, characterization and anticancer activity, Eur. J. Med. Chem. 137 (2017) 45-62.

[15] D. Coskun, M. Erkisa, E. Ulukaya, M.F. Coskun, F. Ari, Synthesis and antitumor evaluation of 2,3-diarylbenzofuran derivatives on HeLa cells, Eur. J. Med. Chem. 136 (2017) 212-222.

[16] G.X. He, J.M. Yuan, H.M. Zhu, K. Wei, L.Y. Wang, S.L. Kong, D.L. Mo, C.X. Pan, G.F. Su, Bioorg. Med. Chem. Lett 27 (2017) 1660-1664.

[17] H.J. Ha, D.W. Kang, H.M. Kim, J.M. Kang, J. Ann, H.J. Hyun, J.H. Lee, S.H. Kim, H. Kim, K. Choi, H.S. Hong, Y. Kim, D.G. Jo, J. Lee, J. Lee, Discovery of an orally bioavailable benzofuran analogue that serves as a $\beta$-amyloid aggregation inhibitor for the potential treatment of Alzheimer's disease, J. Med. Chem. 61 (2018) 396-402.

[18] A. Kumar, F. Pintus, A. Di Petrillo, R. Medda, P. Caria, M.J. Matos, D. Viña, E. Pieroni, F. Delogu, B. Era, G.L. Delogu, A. Fais, Novel 2-pheynlbenzofuran derivatives as selective butyrylcholinesterase inhibitors for Alzheimer's disease, Sci. Rep. 8 (2018) 4424.

[19] F. Mehrabi, Y. Pourshojaei, A. Moradi, M. Sharifzadeh, L. Khosravani, R. Sabourian, S. Rahmani-Nezhad, M. Mohammadi-Khanaposhtani, M. Mahdavi, A. Asadipour, H.R. Rahimi, S. Moghimi, A. Foroumadi, Design, synthesis, molecular modeling and anticholinesterase activity of benzylidenebenzofuran-3-ones containing cyclic amine side chain, Future Med. Chem. 9 (2017) 659-671.

[20] X. Zha, D. Lamba, L. Zhang, Y. Lou, C. Xu, D. Kang, Novel tacrine-benzofuran hybrids as potent multitarget-directed ligands for the treatment of Alzheimer's disease: design, synthesis, biological evaluation, and x-ray crystallography, J. Med. Chem. 59 (2016) 114-131.

[21] K.V. Sashidhara, R.K. Modukuri, R. Sonkar, K.B. Rao, G. Bhatia, Hybrid benzofuran-bisindole derivatives: new prototypes with promising antihyperlipidemic activities, Eur. J. Med. Chem. 68 (2013) 38-46.

[22] K.M. Dawood, H. Abdel-Gawad, E.A. Rageb, M. Ellithey, H.A. Mohamed, Synthesis, anticonvulsant, and anti-inflammatory evaluation of some new benzotriazole and benzofuran-based heterocycles, Bioorg. Med. Chem. 14 (2006) 3672-3680.

[23] K. Manna, Y.K. Agrawal, Design, synthesis, and antitubercular evaluation of novel series of 3-benzofuran-5-aryl-1-pyrazolyl-pyridylmethanone and 3benzofuran-5-aryl-1-pyrazolylcarbonyl-4-oxo-naphthyridin analogs, Eur. J. Med. Chem. 45 (2010) 3831-3839.

[24] Y.S. Xiea, D. Kumar, V.D.V. Bodduri, P.S. Tarani, B.X. Zhao, J.Y. Miao, Microwave-assisted parallel synthesis of benzofuran-2-carboxamide derivatives bearing anti-inflammatory, analgesic and antipyretic agents, Tetrahedron Lett. 55 (2014) 2796-2800.

[25] Y. He, L.F. Zeng, Z.H. Yu, R. He, S. Liu, Z.Y. Zhang, Bicyclic benzofuran and indole-based salicylic acids as protein tyrosine phosphatase inhibitors, Bioorg. Med. Chem. 20 (2012) 1940-1946.

[26] R. Naik, D.S. Harmalkar, X. Xu, K. Jang, K. Lee, Bioactive benzofuran derivatives: moracins A-Z in medicinal chemistry, Eur. J. Med. Chem. 90 (2015) 379-393.

[27] M. Chand, R. Asha Hiremathad, M. Singh, M.A. Santos, R.S. Keri, A review on antioxidant potential of bioactive heterocycle benzofuran: natural and synthetic derivatives, Pharmacol. J. Rep. 69 (2017) 281-295.

[28] M. Miceli, E. Roma, P. Rosa, M. Feroci, M.A. Loreto, D. Tofani, T. Gasperi, Synthesis of benzofuran-2-one derivatives and evaluation of their antioxidant capacity by comparing DPPH assay and cyclic voltammetry, Molecules (2018) 23. E710.

[29] J. Rangaswamy, H.V. Kumar, S.T. Harini, N. Naik, Synthesis of benzofuran based 1,3,5-substituted pyrazole derivatives: as a new class of potent antioxidants and antimicrobials-a novel accost to amend biocompatibility, Bioorg. Med. Chem. Lett 22 (2012) 4773-4777.

[30] C. Kohlhardt-Floehr, F. Boehm, S. Troppens, J. Lademann, T.G. Truscott, Prooxidant and antioxidant behaviour of usnic acid from lichens under UVB- 
light irradiation-studies on human cells, J. Photochem. Photobiol., B 101 (2010) 97-102.

[31] L. Koulu, UV radiation, tanning and DNA damage, Duodecim 130 (2014) 637-641.

[32] A. Knak, J. Regensburger, T. Maisch, W. Bäumler, Exposure of vitamins to UVB and UVA radiation generates singlet oxygen, Photochem. Photobiol. Sci. 13 (2014) 820-829.

[33] J.S. Reis, M.A. Corrêa, M.C. Chung, J.L. Dos Santos, Synthesis, antioxidant and photoprotection activities of hybrid derivatives useful to prevent skin cancer, Bioorg. Med. Chem. 22 (2014) 2733-2738.

[34] A. Bino, A. Baldisserotto, E. Scalambra, V. Dissette, D.E. Vedaldi, A. Salvador, E. Durini, S. Manfredini, S. Vertuani, J. Enzym. Inhib. Med. Chem. 32 (2017) $527-537$.

[35] V. Onnis, M. Demurtas, A. Deplano, G. Balboni, A. Baldisserotto, S. Manfredini, S. Pacifico, S. Liekens, J. Balzarini, Design, synthesis and evaluation of antiproliferative activity of new benzimidazolehydrazones, Molecules 21 (2016). E579.

[36] W.-C. Wan, W. Chen, L.-X. Liu, Y. Li, L.-J. Yang, X.-Y. Deng, H. Bin Zhang, X.D. Yang, Synthesis and cytotoxic activity of novel hybrid compounds between 2-alkylbenzofuran and imidazole, Med. Chem. Res. 23 (2014) 1599-1611.

[37] M. Taha, S.A.A. Shah, S. Imran, M. Afifi, S. Chigurupati, M. Selvaraj, F. Rahim, H. Ullah, K. Zaman, S. Vijayabalan, Synthesis and in vitro study of benzofuran hydrazone derivatives as novel alpha-amylase inhibitor, Bioorg. Chem. 75 (2017) 78-85.

[38] M. Taha, N. Ismail, W. Jamil, S. Yousuf, F. Jaafar, M. Ali, S. Kashif, E. Hussain, Synthesis, evaluation of antioxidant activity and crystal structure of 2,4dimethylbenzoylhydrazones, Molecules 18 (2013) 10912-10929.

[39] K.A. Korthals, W.D. Wulff, Traceless stereoinduction in the one-pot assembly of all three rings of hexahydrodibenzopyrans, J. Am. Chem. Soc. 130 (2008) 2898-2899.

[40] P.C. Lima, L.M. Lima, K.C.M. da Silva, P.H.O. Leda, A.L.P. de Miranda, C.A.M. Fraga, J. Eliezer, E.J. Barreiro, Synthesis and analgesic activity of novel $\mathrm{N}$-acylarylhydrazones and isosters, derived from natural safrole, Eur. J. Med. Chem. 35 (2000) 187-203.

[41] B.L. Diffey, J. Robson, A new substrate to measures sunscreen protection factors throughout the ultraviolets spectrum, J. Soc. Cosmet. Chem. 40 (1989) 127-133.

[42] H.C. Polonini, R.S. Lopes, A. Beatriz, R.S. Gomes, A.O. Silva, R.V. de Lima G.A. Nunes, M.A.F. Brandão, N.R.B. Raposo, D.P. De Lima, Synthesis and evaluation of octocrylene-inspired compounds for UV-filter activity, Quim. Nova 37 (2014) 1004-1009.
[43] Food and Drug Administration, 21 CFR Parts 347 and 352. Sunscreen Drug Product for Over-the-counter Human Use, Proposed Amendent of Final Monograph, Proposed Rule, Food Administration, Silver Spring, 2007.

[44] A. Springsteen, R. Yurek, M. Frazier, K.F. Carr, In vitro measurement of sun protection factor of sunscreens by diffuse transmittance, Anal. Chim. Acta 380 (1999) 155-164.

[45] E. Fibach, E. Prus, N. Bianchi, C. Zuccato, G. Breveglieri, F. Salvatori, A. Finotti, M. Lipucci Di Paola, E. Brognara, I. Lampronti, M. Borgatti, R. Gambari, Resveratrol: antioxidant activity and Induction of fetal hemoglobin in erythroid cells from normal donors and $\beta$-thalassemia patients, Int. J. Mol. Med. 29 (2012) 974-982.

[46] E. Bottini, F. Cozzi, G. Maggioni, On the formation of a peculiar benzidinepositive band in incubation in vitro of different hemoglobins with various plasmas, Boll. Soc. Ital. Biol. Sper. 39 (1963) 979-982.

[47] S. Parekh, D. Bhavsar, M. Savant, M. Thakrar, A. Shah, et al., Synthesis of some novel benzofuran-2-yl(4,5-dihyro-3,5-substituted diphenylpyrazol-1-yl) methanones and studies on the antiproliferative effects and reversal of multidrug resistance of human MDR1-gene transfected mouse lymphoma cells in vitro, Eur. J. Med. Chem. 46 (2011) 1942-1948.

[48] K. Ravi, R.S.A. Ujiinamatada, S.A. Yankanagouda, Synthesis and antimicrobial activity of new benzofuranyl-1,3-benzoxazines and 1,3-Benzoxazin-2-ones, J. Heterocycl. Chem. 43 (2006) 437-441.

[49] M. Wang, J. Li, M. Rangarajan, et al., Antioxidative phenolic compounds from Sage (Salvia officinalis), J. Agric. Food Chem. 46 (1998) 4869-4873.

[50] X. Guihua, Y. Xing Qian, C. Jianchu, L. Donghong, Effect of heat treatment on the phenolic compounds and antioxidant capacity of citrus peel extract, J. Agric. Food Chem. 55 (2007) 330-335.

[51] F. Pessina, K. Marazova, P. Ninfali, L. Avanzi, S. Manfredini, G. Sgaragli, In vitro neuroprotection by novel antioxidants in Guinea-pig urinary bladder subjected to anoxiaglucopenia/reperfusion damage, Naunyn-Schmiedeberg's Arch. Pharmacol. 6 (2004) 521-528.

[52] P.J. Matts, V. Alard, M.W. Brown, L. Ferrero, H. Gers-Barlag, N. Issachar, D. Moyal, R. Wolber, Int. J. Cosmet. Sci. 32 (2010) 35-46.

[53] I. Lampronti, D. Martello, N. Bianchi, M. Borgatti, E. Lambertini, R. Piva, S. Jabbar, M.S. Choudhuri, M.T. Khan, R. Gambari, In vitro antiproliferative effects on human tumor cell lines of extracts from the Bangladeshi medicinal plant Aegle marmelos Correa, Phytomedicine 10 (2003) 300-308.

[54] C. Zuccato, N. Bianchi, M. Borgatti, I. Lampronti, F. Massei, C. Favre, R. Gambari, Everolimus is a potent inducer of erythroid differentiation and gamma-globin gene expression in human erythroid cells, Acta Haematol. 117 (2007) $168-176$. 